\title{
Comparison of healing rate in diabetes-related foot ulcers with low frequency ultrasonic debridement versus non-surgical sharps debridement: a randomised trial protocol
}

Lucia Michailidis $^{1 *}$, Cylie M Williams ${ }^{2,3}$, Shan M Bergin ${ }^{1}$ and Terry P Haines ${ }^{3,4}$

\begin{abstract}
Background: Foot ulceration has been reported as the leading cause of hospital admission and amputation in individuals with diabetes. Diabetes-related foot ulcers require multidisciplinary management and best practice care, including debridement, offloading, dressings, management of infection, modified footwear and management of extrinsic factors.

Ulcer debridement is a commonly applied management approach involving removal of non-viable tissue from the ulcer bed. Different methods of debridement have been reported in the literature including autolytic debridement via moist wound healing, mechanical debridement utilising wet to dry dressings, theatre based sharps debridement, biological debridement, non-surgical sharps debridement and newer technology such as low frequency ultrasonic debridement.
\end{abstract}

Methods: People with diabetes and a foot ulcer, referred to and treated by the Podiatry Department at Monash Health and who meet the inclusion criteria will be invited to participate in this randomised controlled trial. Participants will be randomly and equally allocated to either the non-surgical sharps debridement (control) or low frequency ultrasonic debridement (intervention) group ( $n=322 \mathrm{ulcers} / \mathrm{n}=108$ participants).

Where participants have more than one ulcer, only the participant will be randomised, not the ulcer. An investigator not involved in participant recruitment or assessment will be responsible for preparing the random allocation sequence and envelopes.

Each participant will receive weekly treatment for six months including best practice podiatric management. Each ulcer will be measured on a weekly basis by calculating total area in centimetres squared. Measurement will be undertaken by a trained research assistant to ensure outcomes are blinded from the treating podiatrist. Another member of the research team will assess the final primary outcome.

Discussion: The primary aim of this study is to compare healing rates for diabetes-related foot ulcers using non-surgical sharps debridement versus low frequency ultrasonic debridement over a six month period. The primary outcome measure for this study is the proportion of ulcers healed by the six month follow-up period.

Secondary outcomes will include a quality of life measure, assessment of pain and health care resource use between the two treatment modalities.

Trial registration: Australian New Zealand Clinical Trial Registry: ACTRN12612000490875.

Keywords: Debridement, Diabetes complications, Wound healing, Ultrasonics

\footnotetext{
* Correspondence: Lucia.michailidis@monashhealth.org

'Podiatry Department, Monash Health, Warrigal Road, Cheltenham, Victoria

3192, Australia

Full list of author information is available at the end of the article
} 


\section{Introduction}

\section{Background}

Diabetes is rapidly increasing in global prevalence, morbidity and mortality. In 2011, 366 million people globally were living with diabetes, a figure that is equivalent to $8.3 \%$ of the world's adult population. It was estimated the international community would not reach this figure until 2030 [1].

In Australia the prevalence of type 2 diabetes has increased over the past two decades and continues to rise. Approximately $7 \%$ of the Australian population is thought to have type 2 diabetes and it is estimated that $15 \%$ of people with diabetes will develop a foot ulcer during their lifetime [2]. The consequences of having diabetes in Australia are significant with over 500,000 hospital admissions and 12,000 deaths attributed to the condition in 2004 alone [1].

The pathophysiology of foot ulceration is complex and usually multi-factorial. Peripheral sensory neuropathy, foot deformity and external trauma, when occurring concurrently, have been identified as being the three most common factors that predispose to diabetes-related foot ulcers (DRFU) [3]. Peripheral arterial disease has also been shown to lead to the development of ischaemic and neuro-ischaemic DRFU [2]. Regardless of the true aetiology, the same complications can arise with all DRFU, including soft tissue infection, osteomyelitis, tissue necrosis and failure of ulcer healing, all of which may require hospital admission and potentially result in amputation [4].

Diabetes has been acknowledged to be the most common cause of non-traumatic lower-limb amputation in Australia [5]. Furthermore, acute complications affecting foot ulceration have been reported as the leading cause of diabetes-related hospital admissions and amputation [4]. For the years 2004-2005 the Australian Institute of Health and Welfare reported that DRFU resulted in 9900 acute hospital admissions [4]. In the same period 3400 diabetes-related lower limb amputations were also reported [2].

More recently it has also been suggested that diabetesrelated lower limb amputations have increased by $30 \%$ between the years 1998 - 2005 [6]. The estimated acute care cost of a single lower extremity amputation in Australia could be as much as $\$ 26,700$ [4]. This figure does not include costs for rehabilitation, purchase of orthotics/prosthetics or time lost from work. Recent economic evaluations of the cost of a lower limb amputation for a single person found that Australia sits in third place behind France where such a procedure is estimated to cost $\$ 46,064$ for a single diabetes-related lower extremity amputation and in Germany the same is estimated at a cost of $\$ 31,809$ [2]. The cost of amputation secondary to diabetes complications in the United States of America is said to range from $\$ 20,000$ - $\$ 60,000$ per patient and similarly does not include the personal, social, or economic aspects of the patient's life [7].

None of the costs noted above consider the direct financial burden on patients with a DRFU. The ongoing costs of ulcer management in the community have not been investigated in the literature to date, however clinicians, patients and their families feel the impact of these costs every day. It has been reported however, that in one study investigated the quality of life of patients with DRFU $50 \%$ of patients were no longer in work because of their ulcer. Although treatment was free the costs associated with travelling to hospital appointments and buying additional footwear [8] placed an additional financial strain on patients.

Given the complications associated with DRFU and the time these ulcers can take to heal it is not surprising that patients report a greatly reduced quality of life [9]. It has been found that all quality of life domains can be adversely impacted primarily because of a reduction in mobility and the consequent need to adapt activities of daily living [8]. Additionally it is thought that the presence of a foot ulcer imposes restrictions on patient participation and enjoyment of their usual hobbies mainly because of mobility difficulties and the requirements for treatment [9]. This has been shown to have a negative psychological effect with an increase in patients with depression and a lower satisfaction with their personal lives [9]. Reviewing and improving ulcer management interventions that have the potential to result in more effective and faster healing could have the added benefit of improving the quality of life of patients with a DRFU.

Debridement has been identified as a leading treatment for management of DRFU [2]. Debridement has been defined as the removal of devitalised, contaminated or foreign material from within or adjacent to the ulcer until surrounding healthy tissue is exposed [10]. It serves several functions including reduced pressure on the ulcer base, more thorough inspection to determine true ulcer depth and size, facilitation of drainage and creation of an acute ulcer environment [6].

Existing approaches to ulcer debridement can be performed directly by a clinician including theatre-based sharps debridement (TBSD) also known as surgical excision and non-surgical sharps debridement (NSSD) or scalpel debridement in a clinical setting. There are also various topical products that act as debriding agents. These have included wet-dry dressings that act as mechanical debriding agents, dressings that encourage moist wound healing and autolytic debridement, biological debridement through use of sterile larvae and also the use of chemical enzymes [10-13].

Theatre-based sharps debridement has been utilised for removal of deep necrotic tissue, gangrene and deep infection [14] but has not been routinely used as part of 
standard care. Non-surgical sharps debridement is required more regularly to remove non-viable necrotic tissue from the ulcer surface and is recommended as part of standard ulcer care [13]. The need for and appropriate method of ulcer debridement should be determined based on the clinical presentation [12] and potentially the clinical skillset and equipment available [13].

Sonoca $185^{\mathrm{mm}}$ (SÖering) was introduced in Australia recently as an alternative method for ulcer debridement. The technology works by delivering low frequency ultrasound, or sound waves, through a constant flow of saline. Ultrasound results when electrical energy is converted to sound waves at frequencies above the range of human hearing $(20 \mathrm{kHz})$ with Sonoca $185^{\mathrm{mm}}$ functioning at $25 \mathrm{kHz}$ [15]. These sound waves can then be transmitted to tissue, via a liquid medium, through a treatment applicator. It is the non-thermal effects of ultrasound that have been shown to cause two phenomena at the ulcer surface; acoustic streaming [15-17] (a steady mechanical force delivered in a fluid medium i.e. sterile saline) and cavitation [15-17] (formation of gas bubbles in the fluid creating micro-shockwaves). The combined effects of acoustic streaming and cavitation are thought to alter cell membrane activity and increase the activity of each cell [16]. Subsequently this is thought to have three clinical effects: debridement, a bactericidal effect and an ulcer healing stimulator effect [17-19].

The biological effects indicated through in vitro and animal studies could contribute to ulcer healing [20]. These effects include stimulation of cellular activity and protein synthesis, the activation of inflammatory cells and the production of chemical mediators that activate fibroblasts and may lead to ulcer healing $[15,19,20]$. Additionally the mechanical forces produced by the ultrasound energy at the cellular and molecular levels may promote ulcer healing by fostering cell division, angiogenesis, the release of growth factors [20] and stimulating collagen synthesis $[15,19]$. In vitro data has also found that low frequency ultrasonic debridement (LFUD) is effective in reducing microbe count for methicillinresistant staphylococcus aureus, vancomycin resistant enterococci, pseudomonas and other commonly occurring bacteria $[17,18]$.

When comparing LFUD with TBSD significant clinical advantages have been noted in terms of efficacy and safety for debriding ulcers without deep infection or necrosis. Successful TBSD is reliant upon the skill of the surgeon and their ability to distinguish between tissue types. Procedural risks of TBSD have included pain, bleeding [21], damage to underlying structures with a resultant loss of function [13,22], post-surgical infection and the use and associated risks of general anaesthesia [13].

Comparisons have been made with the use of LFUD and TBSD in DRFU in a randomised controlled trial, which found a mean healing rate that was 2.5 times faster using LFUD compared to TBSD over a two week treatment period. Limitations of this study include the very short follow-up of only two weeks and the small sample size $(\mathrm{N}=59)$ [23].

A randomised double-blind controlled trial has compared low-frequency low-intensity ultrasonic debridement to a sham treatment (saline mist without ultrasound) in patients with recalcitrant DRFU. Ennis et al. found that after 12 weeks of treatment $40.7 \%$ of patients who underwent LFUD had healed compared to only $14.3 \%$ in the sham treatment group. Whilst this is promising data the overall numbers of participants were small $(\mathrm{N}=55)[24]$.

A recent meta-analysis investigating the use of noncontact low-frequency high-intensity ultrasonic debridement, reported significant improvement compared to NSSD at three and five months, but no difference at six months. There were only two studies suitable for the meta-analysis, one focused on DRFU $(\mathrm{N}=40)$ and the other venous leg ulcers $(\mathrm{N}=76)$. Again the overall numbers were small [16].

Another meta-analysis concluded that non-contact LFUD is an efficacious treatment for chronic wounds of varying aetiologies [20]. Despite the quality of the initial evidence being of low quality suggests that LFUD does demonstrate short-term clinical benefits when used as an adjunctive therapy. Recommendations from both meta-analyses were the same; there is no evidence that compares LFUD with standard ulcer management. Additionally, there is a need for further research using larger randomised clinical trials of longer period of time.

Given the evidence available it could be expected that LFUD might be a lower-cost treatment when compared to TBSD in terms of the cost associated with the actual treatment itself and potential savings from healing ulcers faster.

Non-surgical sharps debridement has been considered the leading comparator to TBSD for several reasons; the technique is simple and requires the use of basic instruments by a trained professional; it is time efficient and can be performed in clinic or at the bed-side; does not require the resources of an operating theatre and has a lower overall cost.

Evidence on the most appropriate method, frequency and extent of DRFU debridement is limited and insufficient to draw any conclusions. The National EvidenceBased Guidelines for the Prevention, Identification and Management of Foot Complications in Diabetes recommends that NSSD should be considered first and should occur repeatedly and as often as required to remove all non-viable tissue [2]. This recommendation is based on expert opinion in the absence of evidence pertaining to DRFU debridement. 
A recent Cochrane Review [10] on debridement of diabetic foot ulcers notes that while ulcer debridement is recommended as an effective intervention to assist healing, no guidelines identify a specific method of debridement. The methods of debridement reviewed included surgical debridement, topical hydrogels and larval therapy [10]. Neither NSSD nor LFUD were investigated in the Cochrane Review.

The method of choice for ulcer debridement remains inconclusive. Evidence suggests that each ulcer needs to be individually assessed in terms of type, size, position, appearance, patient pain and tolerance, cost effectiveness and available expertise and equipment to determine the most suitable method of debridement [25].

The decision to utilise NSSD as the active control group in this study was based on the expert opinion in clinical guidelines and the low cost and easy accessibility of the treatment for clinicians. The limited data around LFUD leaves a gap in the evidence that warrants further investigation. The limited data available on LFUD with NSSD as standard practice makes this debridement modality a choice comparator.

It is hypothesised that use of LFUD in the treatment of DRFU would improve healing rates when compared with NSSD. There will be four aims within this study. The primary aim is to determine if there is a difference in healing rates for DRFU, using NSSD compared to LFUD. Secondary aims include assessing for differences in pain during and post-treatment, determining if there is a difference between the quality of life of participants who have an ulcer undergoing either method of debridement and if there is a difference in overall costs between NSSD and LFUD.

This clinical trial will provide important information in the field of ulcer management; provide a better understanding of the efficacy of NSSD and the newer technology of LFUD. It will also provide health services with a better understanding of the financial impacts of both treatments. This protocol has been designed and reported to ensure it corresponds to the 33 items of the Standard Protocol Items: Recommendations for Interventional Trials (SPIRIT) checklist [26].

\section{Methods}

\section{Study design}

This is a randomised controlled trial comparing NSSD (active control group) and LFUD (treatment group) in DRFU with a six month follow-up period. A consort flow chart for the design of this study is presented in Figure 1.

\section{Ethical consideration}

Ethical approval for this study has been obtained by the Monash Health Human Research Ethics Committee HREC 12101B.

\section{Participants and setting}

Patients with diabetes and a foot ulcer/s, who are referred to and treated by the Podiatry Department at Monash Health, will be invited to participate in this study. Patients may be inpatients and receiving podiatry care on the ward or outpatients referred by the patient's primary medical care team.

This study is a single centre trial. The average length of stay for an acute hospital admission in Australia is 6 days [27]. Participants may be recruited during their hospital admission but it is anticipated they will receive treatment primarily in the outpatient setting. Inpatients, however, can receive either treatment if they meet inclusion criteria for this study as both study interventions can be undertaken by the bedside as well as in an outpatient clinical setting.

A standard initial podiatric assessment will occur at baseline including a neurovascular assessment, medical and surgical history, medications history, diabetes management and control history including glycated haemoglobin (Hba1c), footwear assessment, ulcer aetiology, ulcer duration and previous management. If the participant meets the inclusion criteria (Table 1) as determined by the treating podiatrist, the patient will be informed about the research project and written consent will be obtained to participate in the study.

Ulcers must be chronic, or greater than 1 month in duration to be included in the study. This is to capture the most accurate data around DRFU, which have been shown in the literature to take longer than 4 weeks to heal [29]. Should a patient have an ulcer infection at the time of recruitment, or develop an infection during the trial they will receive appropriate antibiotic therapy and will be able to continue in the trial. If appropriate infection management is not commenced, irrespective of the reasons, the patient will not be able to continue in the trial.

\section{Interventions}

The two interventions are the two different methods of ulcer debridement, LFUD and NSSD. The techniques for both treatments are as described in Table 2 .

\section{Outcome measures}

\section{Primary outcome measure}

The primary outcome measure for this study is the proportion of ulcers healed over the six month follow-up period. An ulcer is defined as healed in the presence of intact skin, i.e. functional epithelial tissue [30], a total surface area of $0 \mathrm{~cm}^{2}$ and restoration of functional and anatomic continuity [31]. Ulcer healing status will be determined by assessing the total ulcer area.

Ulcer surface area will be assessed using photographs taken with a digital camera using a standard technique 


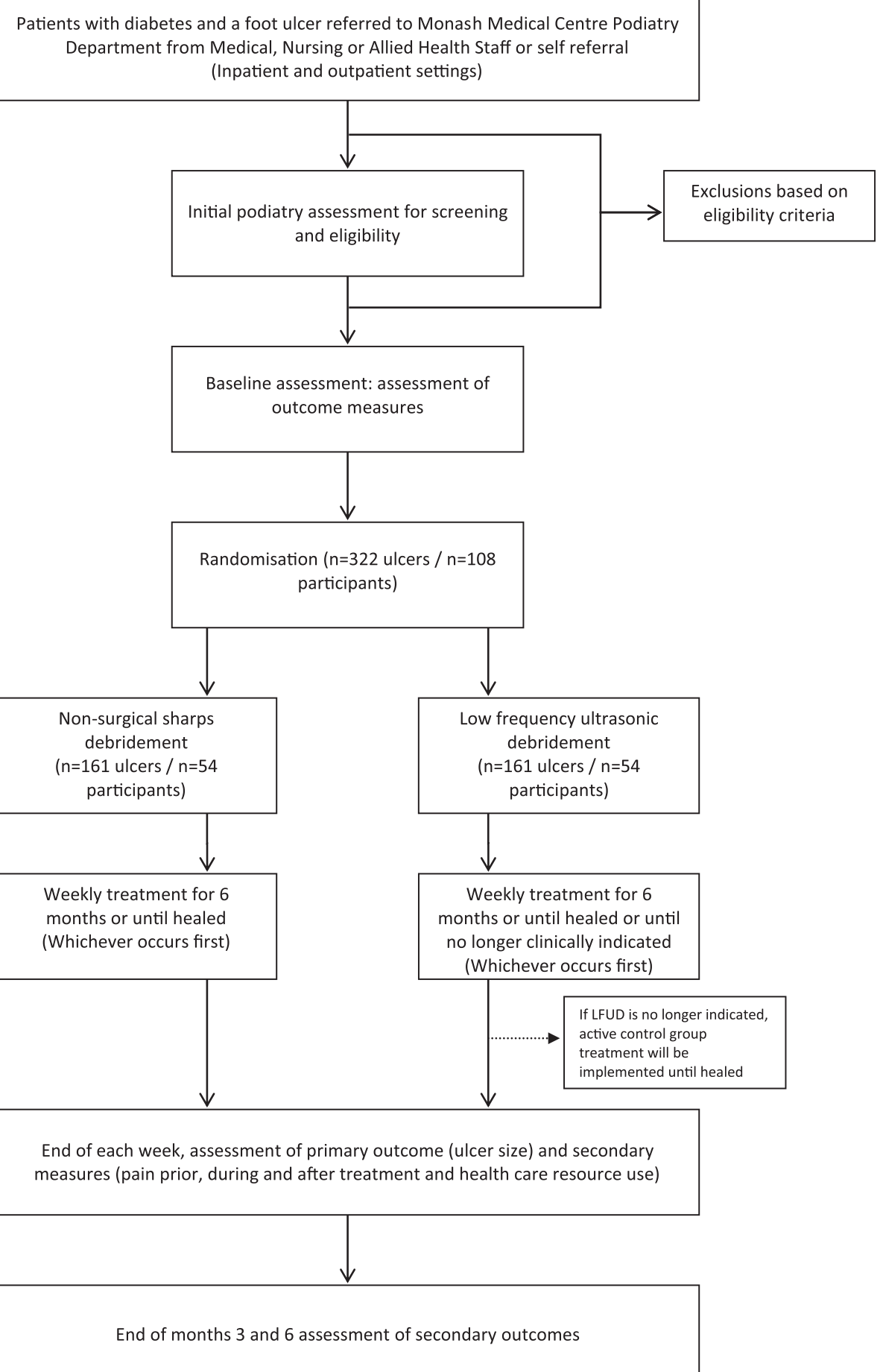

Figure 1 Consort flow chart for the study.

(Table 3). A one centimetre by one centimetre, transparent grid will be utilised over the printed photograph and the total area calculated. Total surface area measurements will be performed following each weekly treatment. A research assistant blinded to the treatment allocation will collect the data for the primary outcome measure. This is to ensure the treating podiatrist is blinded to the primary outcome during subsequent treatments.

The research assistant has been trained by the treating podiatrist and given written instructions on how to use 
Table 1 Participant inclusion and exclusion criteria

\begin{tabular}{ll}
\hline Inclusion criteria & Exclusion criteria \\
\hline General: & General: \\
$\geq 30$ years of age & Patients taking immunosuppressive medications \\
Able to provide informed consent & Known allergy to ulcer dressing products \\
Ulcers present for greater than 1 month & Pre-existing ulcer pain preventing either type of debridement \\
Ulcers $\geq 1 \mathrm{~cm}^{2}$ & \\
Vascular: & Vascular: \\
Palpable pedal pulses OR biphasic or triphasic pedal pulses on & Non-palpable pedal pulses OR monophasic pedal pulses on Doppler OR toe \\
doppler OR toe pressure $\geq 45$ mmHg & pressure $\leq 45$ mmHg \\
Ulcer classification: & Ulcer Classification: \\
Infected ulcers being appropriately managed & Dry gangrenous ulcer \\
Those meeting The University of Texas Wound classification criteria [28]: & Fungating ulcers \\
A1, A2, A3 (wounds of varying depth without infection or ischaemia) & Malignant ulcers \\
B1, B2, B3 (wounds of varying depth with infection only) & Those meeting the University of Texas wound classification criteria [28]: \\
& AO, BO, CO, DO (pre or post-ulcerative lesion with complete epithelialisation, with \\
& or without infection and ischaemia) \\
& C1, C2, C3 (wounds of varying depth with ischaemia only) \\
& D1, D2, D3 (wound of varying depth with infection and ischaemia)
\end{tabular}

the transparent grid to calculate total ulcer area. To determine reliability fifteen ulcers have been photographed and both the research assistant and treating podiatrist followed the same technique to calculate ulcer area. Inter-rater measurement reliability between the treating podiatrist and research assistant was found to have an ICC of 0.91 .

The ulcer depth will be measured by the treating podiatrist following each treatment, as depth cannot be accurately assessed using a photograph. A disposable measurement probe will be used to assess ulcer depth, undermining, sinus or tracking.

A review of available literature around ulcer measurement is scarce and of low evidence. The measurement technique being used in this study, tracing and subsequent counting of centimetre squares, has a high interrater and intra-rater reliability when compared to other forms of ulcer measurement [32,33].
A standard technique will be used for each method of debridement and ulcer measurement ensuring consistency (Tables 2 and 3).

Ulcers being treated in the intervention group will be reviewed after six weeks of treatment. If LFUD is no longer clinically indicated then treatment will be ceased and the ulcers will then receive the control treatment (NSSD). This change is to reflect the pragmatic nature of the treatment and NSSD is considered standard ulcer care. Clinical indications for ceasing LFUD treatment include pain, ulcer size and depth, clinical presentation and no ulcer improvement.

\section{Secondary outcome measures}

Secondary outcome measures will include assessing ulcer pain, quality of life and economic evaluation.

Ulcer pain will be measured weekly using a $100 \mathrm{~mm}$ Visual Analogue Scale (VAS). Pain will be assessed prior

Table 2 Standard step-by-step technique for LFUD and NSSD

\begin{tabular}{|c|c|}
\hline LFUD & NSSD \\
\hline 1) Constantly move the handpiece to prevent ultrasound burning tissue & 1) Start debriding at the distal most aspect of the ulcer \\
\hline 2) Start debriding at the distal most aspect of the ulcer & 2) Moving scalpel proximally with each motion \\
\hline 3) Moving the handpiece left to right and from the distal to proximal aspect of the ulcer & $\begin{array}{l}\text { 3) Once the distal to proximal ulcer has been debrided then } \\
\text { debride from left side to right side }\end{array}$ \\
\hline $\begin{array}{l}\text { 4) Once the entire ulcer surface has been debrided re-commence the same technique } \\
\text { from the distal most aspect of the ulcer }\end{array}$ & $\begin{array}{l}\text { 4) Continue until as much necrotic tissue has been removed } \\
\text { as possible }\end{array}$ \\
\hline 5) Continue until as much necrotic tissue has be removed as possible & \multirow{2}{*}{$\begin{array}{l}\text { 5) Any peri-wound tissue that requires removal (i.e. callus, } \\
\text { maceration) will occur using a scalpel. }\end{array}$} \\
\hline $\begin{array}{l}\text { 6) Any peri-wound tissue that requires removal (i.e. callus, maceration) will occur using } \\
\text { a scalpel. The wound base will not be debrided with the scalpel. }\end{array}$ & \\
\hline
\end{tabular}




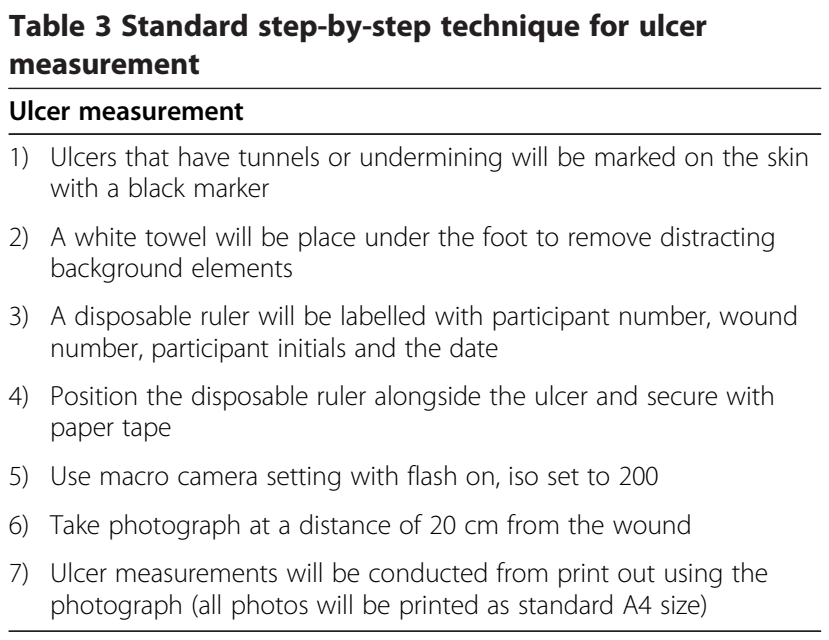

to, during and following each treatment. The far left end of the scale $(0 \mathrm{~mm})$ will be labelled as no pain and the far right end of the scale $(100 \mathrm{~mm})$ will be labelled as worst pain imaginable. The VAS has been widely used and has been shown to be a valid and reliable pain assessment tool [34].

A health-related quality of life tool will be used to gain perspective from each participant. This will be undertaken at the initial treatment, at three months and again at six months. If an ulcer heals prior to the end of the six month study period the tool will be applied at that point. The Eq 5D-5 L [35] assessment tool analyses five health-related quality of life domains including mobility, self-care, usual activities, pain/discomfort and anxiety/ depression. This tool has been widely used and has been validated for use in patient groups with diabetes [36].

All data for the secondary outcome measures will be collected by the treating podiatrist. No blinding will occur for this data.

Each outcome measure and their time points of collection are summarised in Table 4.

\section{Sample size}

The sample size calculation for this study was based upon the primary outcome comparison between groups of the proportion of ulcers completely healed by the six month follow-up. Previous research indicates that nearly $25 \%$ of ulcers treated with NSSD healed within six months [29], while another previous study found that $41 \%$ of ulcers treated with LFUD healed within three months [24]. There is no six month data available for the LFUD approach. A sample size of 147 ulcers per group is required to achieve $80 \%$ power using a twotailed alpha of 0.05 to detect an absolute difference in the proportion of ulcers healed of 0.16 (control $=0.25$, intervention $=0.41$ ). To account for the intra-cluster correlation of multiple ulcers being nested within a single participant we adjust this for a design effect $(1+(n-1) *$ ICC) using $\mathrm{n}=3$ ulcers per participant and ICC estimate of 0.05 ; thus we require 161 ulcers per group. With an average of 3 ulcers per participant we require 54 participants per group.

\section{Randomisation}

Randomisation will be undertaken using a permutedblock randomisation approach. Randomisation blocks of two, four or eight participants will be generated and randomly selected and the resultant allocation order will be entered into opaque, sealed envelopes. An investigator not involved in recruitment or assessment $(\mathrm{CW})$ will be responsible for preparing the random allocation sequence and envelopes. The treatment conditions will be provided as per the random allocation sequence following completion of the initial assessment.

Once eligibility has been confirmed, a verbal explanation of the project will be provided and the treating podiatrist will obtain written consent. All participants who consent will have baseline assessments conducted prior to randomisation, as outlined above. All ulcers (where there is more than one per participant) will be numbered and documented according to anatomical location prior to randomisation. Only the treatment condition will be randomised, not each individual ulcer. Where there is more than one ulcer, all will be treated with the same method as per the randomisation process and included in the study. Following randomisation the initial treatment and measurements will commence as outlined in Tables 2 and 3. All participants will receive treatment and have their ulcers photographed and measured on a weekly basis, as is standard podiatry practice at Monash Health. Both groups will receive best practice ulcer management including appropriate ulcer dressings, pressure off-loading and footwear provision as required.

Identifiable outcome data will be stored within the participant's health record. De-identifiable data will be stored within a password-protected Excel spread sheet within a secure hospital data management system as per requirement of the Human Research Ethics Committee (HREC) for Monash Health. The primary investigator (LM) will be responsible for data entry and a co-investigator (SB) will randomly audit information to monitor data accuracy.

The trial will be managed by the research team and led by the primary investigator (LM). The protocol has undergone external review from the Lions John Cockayne Research Fellowship committee and the research team will give quarterly progress reports. Annual reports will also be required (including adverse events) to the HREC of Monash Health. The research team will meet on a monthly basis to address clinical and data monitoring concerns. 
Table 4 Outcome measures and timeframes

\begin{tabular}{|c|c|c|c|}
\hline Data collection & Measurement tool & $\begin{array}{l}\text { Data collected } \\
\text { method }\end{array}$ & Timeframe \\
\hline \multirow[t]{2}{*}{ Measurement of total ulcer area } & Centimetres squared; & \multirow[t]{2}{*}{ Research assistant } & \multirow{2}{*}{$\begin{array}{l}\text { Weekly: Post-treatment until } \\
\text { healed or at } 6 \text { months }\end{array}$} \\
\hline & Tracing from photographs and counting squares & & \\
\hline \multirow[t]{2}{*}{ Measurement of ulcer depth } & Centimetres; & \multirow[t]{2}{*}{ Treating podiatrist } & \multirow{2}{*}{$\begin{array}{l}\text { Weekly: post-treatment until } \\
\text { healed or at } 6 \text { months }\end{array}$} \\
\hline & Using sterile probe & & \\
\hline Ulcer pain & Visual analogue pain scale $100 \mathrm{~mm}$ & Treating podiatrist & $\begin{array}{l}\text { Weekly: Pre-treatment, during } \\
\text { treatment, post-treatment } \\
\text { until healed or } 6 \text { months }\end{array}$ \\
\hline Quality of life & $E Q-5 D-5<$ tool & Participant questionnaire & $\begin{array}{l}\text { Initial treatment, at } 3 \\
\text { months, at } 6 \text { months }\end{array}$ \\
\hline \multicolumn{4}{|l|}{ Direct health costs } \\
\hline Consumable costs for treatments & In dollars for each treatment & Treating podiatrist & $\begin{array}{l}\text { Weekly, per participant until } \\
\text { healed or at } 6 \text { months }\end{array}$ \\
\hline Medicare Benefit Scheme (MBS) & MBS Care database, in dollars & $\begin{array}{l}\text { Extraction from MBS } \\
\text { database }\end{array}$ & $\begin{array}{l}\text { End of project for each } \\
\text { participant from initial to } \\
\text { final treatment }\end{array}$ \\
\hline Pharmaceutical Benefit Scheme (PBS) & PBS Care database, in dollars & $\begin{array}{l}\text { Extraction from PBS } \\
\text { database }\end{array}$ & $\begin{array}{l}\text { End of project for each } \\
\text { participant from initial to } \\
\text { final treatment }\end{array}$ \\
\hline \multirow[t]{4}{*}{ Inpatient data } & Monash Health: & Hospitalisation costs & Monash Health: \\
\hline & \multirow{2}{*}{$\begin{array}{l}\text { Admission duration, reason for admission, imaging and } \\
\text { interventions, obtained from the patient record and } \\
\text { from the Victorian Admitted Episodes Database }\end{array}$} & & End of project \\
\hline & & & \multirow[t]{2}{*}{$\begin{array}{l}\text { External organisation: End of } \\
\text { project }\end{array}$} \\
\hline & $\begin{array}{l}\text { External organisation: Admission duration, reason for } \\
\text { admission, costs of any surgery for diabetes-related foot } \\
\text { ulcers will be estimated using WEISS funding }\end{array}$ & & \\
\hline $\begin{array}{l}\text { Hospital based services (outpatient } \\
\text { data) }\end{array}$ & Hours - time spent & Treating podiatrist & $\begin{array}{l}\text { Weekly per participant until } \\
\text { healed or at } 6 \text { months }\end{array}$ \\
\hline $\begin{array}{l}\text { Medical imaging and pathology for } \\
\text { outpatients }\end{array}$ & Dollars - hospital based costs & Treating podiatrist & $\begin{array}{l}\text { Monthly per participant until } \\
\text { healed or at } 6 \text { months }\end{array}$ \\
\hline Community based services & Number and cost of appointments & Participant interview & $\begin{array}{l}\text { Monthly until healed or at } \\
6 \text { months }\end{array}$ \\
\hline Private health appointments & $\begin{array}{l}\text { Number and cost of appointments, eligibility for private } \\
\text { health subsidies }\end{array}$ & Participant interview & $\begin{array}{l}\text { Monthly until healed or at } \\
6 \text { months }\end{array}$ \\
\hline $\begin{array}{l}\text { Royal District Nursing Service for ulcer } \\
\text { management }\end{array}$ & Frequency and cost of service & Participant interview & $\begin{array}{l}\text { Monthly until healed or at } \\
6 \text { months }\end{array}$ \\
\hline Ongoing ulcer care products & Valued using market prices & Participant interview & $\begin{array}{l}\text { Monthly until healed or at } \\
6 \text { months }\end{array}$ \\
\hline Parking costs for appointments & Dollars & Participant interview & $\begin{array}{l}\text { Monthly until healed or at } \\
6 \text { months }\end{array}$ \\
\hline $\begin{array}{l}\text { Transportation costs to travel to } \\
\text { appointments }\end{array}$ & $\begin{array}{l}\text { Estimated through Australian Tax Office car rate cents } \\
\text { per km }\end{array}$ & Participant interview & $\begin{array}{l}\text { Monthly until healed or at } \\
6 \text { months }\end{array}$ \\
\hline \multicolumn{4}{|l|}{ Productivity costs } \\
\hline $\begin{array}{l}\text { Time taken from work for participant } \\
\text { and/or any family member }\end{array}$ & Salary and hours taken from work & $\begin{array}{l}\text { Participant/family } \\
\text { interview }\end{array}$ & $\begin{array}{l}\text { Monthly until healed or at } \\
6 \text { months }\end{array}$ \\
\hline
\end{tabular}

\section{Statistical analysis}

The proportion of ulcers that are completely healed by the six month follow-up will be compared between groups using a logistic regression analysis approach with clustering of ulcer within participant. A member of the research team $(\mathrm{TH})$ who will be blinded to the allocation of the participants will assess this.
The rate of change in ulcer size (surface area, using the post-debridement photo) will be compared between groups using a linear mixed model analysis approach where repeated assessments will be nested within ulcer, and ulcers will be nested within participants. The groups will be treated as a fixed factor while assessments, ulcer and participants will be treated as random factors. All 
analyses will be adjusted for whether the wound was infected at baseline, as infection has been demonstrated to delay healing [37] and HbA1c levels at baseline as poor glycaemic control has been demonstrated to delay healing [38].

A pre-planned interim analysis will be undertaken after $70 \%$ of the planned sample size has been recruited. This analysis will use all data available to that point in time and examine the safety and efficacy outcomes from the trial. A data analyst who is blinded to group allocation will be provided with the dataset and mock group codes. The outcome of this analysis will be forwarded to the remaining project investigators who will decide whether there is sufficient evidence to reject the null hypothesis for the primary outcome. The assumptions underlying the sample size calculation (e.g. ICC value) will also be examined at this point and revisions to the sample size will be made if indicated.

\section{Economic analysis}

\section{Cost effectiveness analysis}

Direct and indirect health care costs will be collected at regular intervals, as explained in Table 3.

The formula for assessing cost effectiveness analysis will be:

$\frac{\text { Cost }_{\text {LFUD }}-\text { Cost }_{\text {NSSD }}}{\text { Effect }_{\text {LFUD }}-\text { Effect }_{\text {NSSD }}}=$ Incremental cost per additional ulcer healed

\section{Cost utility analysis}

A health related quality of life assessment obtained from the EQ-5D-5 L tool will be converted to utility scores as explained in Table 4. The economic evaluation will examine the cost per quality adjusted life year (QALY) gained per patient provided with each intervention. QALY measurements will use the EQ-5D-5 L utility-based costeffectiveness analysis. The formula to calculate QALYs gained from the intervention will be:

$$
\frac{\text { Cost }_{\text {LFUD }}-\text { Cost }_{\mathrm{NSSD}}}{\text { QALY }_{\mathrm{LFUD}}-\mathrm{QALY}_{\mathrm{NSSD}}}=\text { Incremental cost per QALY gained }
$$

\section{Discussion}

Diabetes-related foot ulceration is a significant medical and social problem. Consensus among wound specialists supports the importance of ulcer debridement to encourage ulcer healing. Despite this, there is a paucity of evidence comparing different debridement techniques. Whilst there is evidence available around the efficacy of LFUD it has been limited. Furthermore, there is no randomised controlled trial looking at the healing rates of DRFU that undergo NSSD compared to LFUD.

This clinical trial will provide important information in the field of ulcer management and provide a better understanding of the efficacy of using NSSD treatment. It will also provide health services with a better understanding of the financial impacts of both treatments.

Adverse events will be measured and recorded during the study. The adverse events for both treatment groups may include incidents such as sharps injuries to the participant or treating podiatrist, development of ulcer infection, hospital admission due to ulcer deterioration, excess pain and bleeding from debridement at the ulcer surface.

A limitation of this study is the non-consideration given to nutritional status. Patient nutritional status has potential to impact on ulcer healing, however outside of a controlled inpatient environment it is difficult to enforce a strict food regime. All patients will be encouraged to adhere to a suitable diet, however this will not be controlled as part of this study.

A second limitation is that while a thorough assessment of pain will be undertaken, this measure will only focus on the individual ulcer pain before, during and after debridement with either modality. Where participants have more than one ulcer in close proximity to another ulcer the pain assessment may become difficult to distinguish for each ulcer.

\section{Abbreviations}

NSSD: Non-surgical sharps debridement; LFUD: Low frequency ultrasonic debridement; TBSD: Theatre-based sharps debridement; DRFU: Diabetesrelated foot ulceration

\section{Competing interests}

The authors declare no competing interests.

\section{Authors' contributions}

All the authors contributed to study design and methodology. LM and CW obtained funding for the study. All authors contributed to the study protocol. LM is the chief investigator and drafted the paper. SB, TH, and CW provided editorial assistance. All authors have read and approved of the final paper.

\section{Funding}

This study is funded in part by a grant from The Lions John Cockayne Memorial Fellowship Trust. Support in kind is also provided by the Monash Health Podiatry Department and Allied Health Clinical Research Unit.

\section{Author details}

${ }^{1}$ Podiatry Department, Monash Health, Warrigal Road, Cheltenham, Victoria 3192, Australia. ${ }^{2}$ Peninsula Health, Community Health, Frankston, Victoria, Australia. ${ }^{3}$ Physiotherapy Department, Monash University, Clayton, Australia.

${ }^{4}$ Allied Health Research Unit, Monash Health, Cheltenham, Victoria, Australia.

Received: 22 March 2013 Accepted: 23 December 2013

Published: 15 January 2014

\section{References}

1. Lazzarini PA, Gurr JM, Rogers JR, Schox A, Bergin SM: Diabetes foot disease: the Cinderella of Australian diabetes management. J Foot Ankle Res 2012, 5(1):24.

2. National Health and Medical Research Council: National Evidence-Based Guidelines on Prevention, Identification and Management of Foot Complications in Diabetes. Melbourne: NHMRC; 2011.

3. Boulton AJ: The diabetic foot: grand overview, epidemiology and pathogenesis. Diabetes Metab Res Rev 2008, 24(Suppl 1):S3-S6. 
4. Australian Institute of Health and Welfare (AlHW): Diabetes Australian Facts. Canberra: AlHW; 2008.

5. Barr ELM DJM, Zimmet PZ, Polkinghorne KR, Atkins RC, Dunstan DW, Murray SG, Shaw JE: The Australian Diabetes, Obesity and Lifestyle Study: Tracking the Accelerating Epidemic: Its Causes and Outcomes. Melbourne: International Diabetes Institute; 2006.

6. Bergin SM, Gurr JM, Allard BP, Holland EL, Horsley MW, Kamp MC, Lazzarini PA, Nube VL, Sinha AK, Warnock JT, et al: Australian Diabetes Foot Network: management of diabetes-related foot ulceration - a clinical update. Med J Aust 2012, 197(4):226-229.

7. Brem H, Sheehan P, Boulton AJ: Protocol for treatment of diabetic foot ulcers. Am J Surg 2004, 187(5):S1-S10.

8. Brod M: Quality of life issues in patients with diabetes and lower extremity ulcers: patients and care givers. Qual Life Res 1998, 7:356-372.

9. Vileikyte L: Diabetic foot ulcers: a quality of life issue. Diabetes Metab Res Rev 2001, 17:246-249.

10. Edwards J, Stapley S: Debridement of diabetic foot ulcers. Cochrane Database Syst Rev 2010, 1:CD003556.

11. Bradley M, Cullum N, Sheldon T: The debridement of chronic wounds: a systematic review. Health Technol Assess 1999, 3(17 Part 1):1-78.

12. Sibald RG, Goodman L, Woo KYDLK, Smart H, Tariq G, Ayello EA, Burrell RE, Keast DH, Mayer D, et al: Special considerations in wound bed preparation 2011: an update. Adv Skin Wound Care 2011, 24(9):415-436.

13. Falabella AF: Debridement and wound bed preparation. Dermatol Ther 2006, 29(6):317-325.

14. Fisher TK, Scimeca CL, Bharara M, Mills JL, Armstrong DG: A Stepwise Approach for Surgical Management of Diabetic Foot Infections. J Vasc Surg 2010, 52(12S):72S-75S.

15. Hess $C L$, Howard MA, Attinger CE: A review of mechanical adjuncts in wound healing: Hydrotherapy, ultrasound, negative pressure therapy, hyperbaric oxygen, and electrostimulation. Ann Plast Surg 2003, 51(2):210-218

16. Voight J, Wendelken M, Driver $\mathrm{V}$, Alvarez OM: Low-frequency ultrasound $(20-40 \mathrm{kHz})$ as an adjunctive therapy for chronic wound healing: a systematic review of the literature and meta-analysis of eight ranomized controlled trials. Int J Low Extrem Wounds 2011, 10(4):190-199.

17. Breuing KH, Bayer L, Neuwalder J, Arch M, Orgill DP: Early Experience Using Low-Frequency Ultrasound in Chronic Wounds. Ann Plast Surg 2005, 55(2):183-187.

18. Pierson T, Niezgoda JA, Learmonth S, Blunt D, McNabb K: Effect of low-frequency ultrasound applied in vitro to highly antibiotic-resistant acinetobacter isolates recovered from soldiers returning from Iraq. Wound Repair Regen 2008, 13(2):1-2

19. Ennis WJ, Valdes W, Gainer M, Meneses P: Evaluation of clinical effectiveness of MIST ultrasound therapy for the healing of chronic wounds. Adv Skin Wound Care 2006, 19(8):437-446.

20. Driver $\mathrm{V}$, Yao M, Miller CJ: Noncontact low-frequency ultrasound therapy in the treatment of chronic wounds: A meta-analysis. Wound Repair Regen 2011, 19(4):475-480.

21. Steed DL: Debridement. Am J Surg 2004, 187(5a):71S-74S.

22. Ulcer and wound management Expert Group: Therapeutic guidelines: Ulcer and wound management, Volume 1. Melbourne: Therapeutic Guidelines Limited; 2012.

23. Singh A: Usage of Ultrasound in Wound Management: Comparison between Ultrasound Wound Debridement and sharp debridement in Diabetic Foot Ulcers: a randomised clinical trial. Malaysia: University of Malaya, Faculty of Medicine; 2006.

24. Ennis WJ, Formann P, Mozen NJM, Conner-Kerr T, Meneses P: Ultrasound Therapy for Recalcitrant Diabetic Foot Ulcers: Results of a Randomized, Double-Blind, Controlled, Multicentre. Study Ostomy Wound Manage 2005, 51(8):24-39.

25. Madhok BM, Vowden K, Voden P: New techniques for wound debridement. Int Wound J 2013, 10:247-251

26. Chan AW, Tetzlaff JM, Altman DG, Laupacis A, Gotzsche PC, Krleza-Jeric K, Hrobjartsson A, Mann H, Dickersin K, Berlin JA, et al: SPIRIT 2013 Statement: Defining Standard Protocol Items for Clinical Trials. Ann Int Med 2013, 158(3):200-207.

27. Australian Institue of Health and Welfare: Australian Hospital Statistics 2011-2012. Canberra: AlHW; 2013.
28. Oyibo SO, Jude EB, Tarawneh I, Nguyen HC, Harkless LB, Boulton AJ: A Comparison of Two Diabetic Foot Ulcer Classification Systems. Diabetes Care 2001, 24(1):84-88

29. Margolis DJ, Kantor J, Berlin JA: Healing of diabetic neuropathic foot ulcers receiving standard treatment. A meta-analysis. Diabetes Care 1999 22(5):692-695

30. International Working Group on the Diabetic Foot: International Consensus on the Diabetic Foot. The Netherlands: International Working Group on the Diabetic Foot; 2003.

31. Margolis DJ, Berlin JA, Strom BL: Interobserver agreement, sensitivity, and specificity of a "healed" chronic wound. Wound Repair Regen 1996, 4(3):335-338.

32. Etris MB, Pribble J, LaBrecque J: Evaluation of two wound measurement methods in a multi-center, controlled study. Ostomy Wound Manage 1994, 40(7):44-48.

33. Lucas C, Classen J, Harrison D, De Haan R: Pressure ulcer surface area measurement using instant full-scale photography and transparancy tracings. Adv Skin Wound Care 2002, 15(1):17-23.

34. Price DD, McGrath PA, Rafii A, Buckingham B: The validation of visual analogue scales as ratio scale measures for chronic and experimental pain. Pain 1983, 17(1):45-56.

35. Herdman M, Gudex C, Lloyd A, Janssen M, Kind P, Parkin D, Bonsel G, Badia $X$ : Development and preliminary testing of the new five-level version of EQ-5D (EQ-5D-5 L). Qual Life Res 2011, 20(10):1727-1736.

36. Janssen MF, Birnie E, Haagsma JA, Bonsel GJ: Comparing the standard EQ-5D three-level system with a five-level version. Value Health 2008, 11(2):275-278

37. Falanga $\mathrm{V}$ : Wound healing and its impairment in the diabetic foot. Lancet 2005, 366(9498):1736-1743.

38. Marston WA: Risk factors associated with healing chronic diabetic foot ulcers: the importance of hyperglycemia. Ostomy Wound Manage 2006 52(3):26-28

doi:10.1186/1757-1146-7-1

Cite this article as: Michailidis et al:: Comparison of healing rate in diabetes-related foot ulcers with low frequency ultrasonic debridement versus non-surgical sharps debridement: a randomised trial protocol. Journal of Foot and Ankle Research 2014 7:1.

\section{Submit your next manuscript to BioMed Central and take full advantage of:}

- Convenient online submission

- Thorough peer review

- No space constraints or color figure charges

- Immediate publication on acceptance

- Inclusion in PubMed, CAS, Scopus and Google Scholar

- Research which is freely available for redistribution

Submit your manuscript at www.biomedcentral.com/submit
C) BioMed Central 